\title{
Physico-mechanical properties of plywood bonded with ecological adhesives from Acacia mollissima tannins and lignosulfonates ${ }^{\star}$
}

\author{
Naima Rhazi ${ }^{1,2, a}$, Mina Oumam ${ }^{1}$, Abdessadek Sesbou ${ }^{3}$, Hassan Hannache ${ }^{1,4}$, and Fatima Charrier-El Bouhtoury ${ }^{2, b}$ \\ ${ }^{1}$ LIMAT-Thermostructural Materials and Polymers Team, Faculty of Science Ben M'sik, University Hassan II of Casablanca, \\ Boulevard Cdt Driss Harti, BP. 7955, Ben M'sik, Casablanca, Morocco \\ 2 CNRS/Univ. Pau \& Pays Adour, Institut des Sciences Analytiques et de Physico-Chimie pour l'Environnement et les \\ Matériaux, UMR5254, BP 201, 40004 Mont-de-Marsan, France \\ ${ }^{3}$ ENFI, BP 511, Tabriquet, 11015 Salé, Morocco \\ ${ }^{4}$ Materials Science and Nanotechnology Department, University Mohammed VI Polytechnic, Lot 660 Hay Moulay Rachid, \\ 43150 Ben Guerir, Morocco
}

Received: 21 February 2017 / Received in final form: 20 March 2017 / Accepted: 21 March 2017 (C) EDP Sciences 2017

\begin{abstract}
The objective of this research was to develop ecological adhesives for bonding plywood panels using lignosulfonates, a common waste product of the wood pulp industry, and natural tannin extracted from Moroccan bark of Acacia mollissima using different process. Natural tannin and lignin were used in wood adhesives formulation to substitute resins based on phenol and formaldehyde. To achieve this, the lignosulfonates were glyoxalated to enhance their reactivity and the used tannins obtained by three different extraction methods were compared with commercial mimosa tannin. The proportion of Acacia mollissima tannins and lignosulfonates, the pressing time, the pressing temperature, and the pressure used were studied to improve mechanical properties, and bonding quality of plywood panel. The properties of plywood panels produced with these adhesives were tested in accordance with normative tests. Thus, the tensile strength, and the shear strength were measured. The results showed that the performance of the plywood panels made using biobased tannin adhesives was influenced by physical conditions such as pressure, press temperature as well as by chemical conditions, such as the tannin-lignin ratio. It exhibited excellent mechanical properties comparable to commercially available phenol-formaldehyde plywood adhesives. This study showed that biobased adhesives formulations presented good and higher mechanical performance and no formaldehyde emission.
\end{abstract}

\section{Introduction}

Wood adhesives widely used for bonding plywood panels are: phenol-formaldehyde (PF), urea-formaldehyde (UF), resorcinol and melanin $[1,2]$. These adhesives are synthetically produced from non-renewable resources such as petroleum and natural gas. Moreover, formaldehyde is considered a priority pollutant by the United States Environmental Protection Agency. Its emission in the environment and workers exposure to it at manufacturing facilities continues to be a major safety concern [3,4]. With increasing the effects of greenhouse gas emissions and the desire to preserve the oil resources and also to protect human and environment, natural adhesives have been used

\footnotetext{
${ }^{a}$ e-mail: rhazinaima2@gmail.com

b e-mail: fatima.charrier@univ-pau.fr

${ }^{\star}$ Contribution to the topical issue "Materials for Energy harvesting, conversion and storage II (ICOME 2016)", edited by Jean-Michel Nunzi, Rachid Bennacer and Mohammed El Ganaoui
}

to partially or totally substitute formaldehyde [5-10]. Recently, there have been growing interests on tanninbased resins. Natural tannin is an excellent renewable resource, which can be used for replacing petroleumderived phenolic compounds. The major species from which it can be obtained are mimosa (also known by Acacia mollissima, Acacia mearnsii and Black wattle), quebracho and radiata pine $[11,12]$. The chemical structure of Acacia mollissima tannin is shown in Figure 1. The free $\mathrm{C}_{5}$ and $\mathrm{C}_{8}$ sites on the A-ring can react with hardener because of their strong nucleophilicity to form the adhesive. The hexamine was used as hardener to replace the use of formaldehyde. Pichelin et al. 2006 [7] showed that hexamine presented equivalent properties to formaldehyde or paraformaldehyde. Tannin-hexamine-based adhesives are known to their lower bonding properties in wet media, because of the weakness of ethylene bridge formed between the tannins and the hardener. This weakness is due that the mimosa tannin when they are activated by the addition of the hardener, tend to auto-condense instead of reacting with the hardener [13]. 


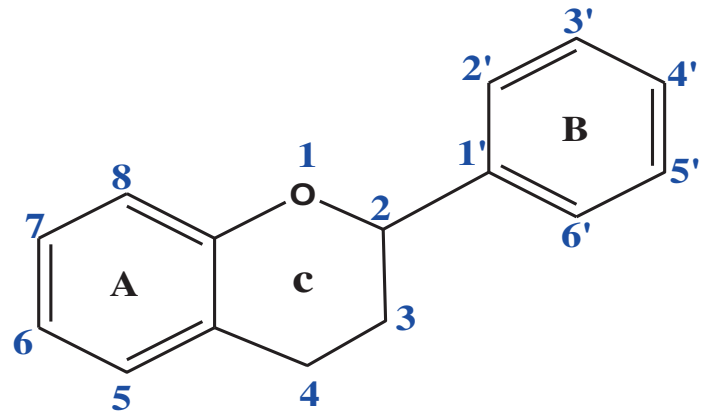

Fig. 1. The chemical structure of mimosa tannins flavonoid.

In recent years, tannin-lignin-based adhesives have been developed. The tannins used were mimosa tannins with either organosolv lignins or kraft lignins [14,15]. The addition of lignin in the adhesive formulations, may improve the mechanical properties of phenolic adhesive [16]. Lignin forms a very stable connection with tannins and improves their reactivity with the hardener [13]. In this context, the present study aims to value natural tannins extracted from Acacia mollissima barks and lignin recovered from paper industry, to elaborate green and ecological adhesives more respectful of the environment with good bonding quality, higher mechanical properties and very low formaldehyde emission. For the first time, various condensed tannins extracted from Moroccan bark of Acacia mollissima were tested to prepare tannin-lignin adhesives for plywood panels. Maceration, infusion and microwave assisted extraction were the extraction processes used to extract condensed tannins [17]. Different screening studies were conducted, to define the factors that have a significant effect on the improvement the bonding quality of plywood. The factors studied are: the effect of mimosa tannin and lignosulfonate ratio, pressing time, pressing pressure, and pressing temperature. The quality of bonding plywood was compared with a standard formulation of synthetic adhesives: PF, and UF. The physical property (solid content) and mechanical properties (modulus of rupture "MOR", tensile measurement, the shear strength and the apparent cohesive failure) of plywood panels were evaluated in accordance normative tests. After determination of significant factors that improve the bonding quality of plywood, an evaluation of formaldehyde emission was made.

\section{Materials and methods}

\subsection{Material preparation}

Bark of Acacia mollissima of ten years and $17 \%$ moisture content were taken from the Moroccan Mamoura forest, from the Kenitra area. Commercial tannins from Acacia mollissima (mimosa) were provided by Sylvachimica (Silvateam, Italy). Lignin used was ammonium lignosulfonates liquid $\left(\mathrm{NH}_{4} \mathrm{LSL}\right)$, delivered by Tembec (Tartas, France). The sodium hydroxide, hexamethylenetetramine (hexamine) and the glyoxal (40\%) were purchased from
Fisher Scientific (Waltham, USA). Wood used for bonding plywood was Beech with $12 \%$ moisture content. Glueline used was $250 \mathrm{~g} / \mathrm{m}^{2}$. The glyoxalation of lignin was carried out as described by Navarette method [14]. In adhesives formulations we used tannin solution, prepared with $45 \%$ of mimosa tannin dissolved in water. A solution of sodium hydroxide $(33 \%)$ was added in order to keep the $\mathrm{pH}$ of the solution at $10.6 \%$ of a hexamethylenetetramine (hexamine), solid mass of hexamine on solid mass of tannin, was added as hardener.

\subsection{Screening factors to improve bonding quality}

The effects of significant factors, which improve the adhesives bonding properties, were evaluated using the solid content of adhesives and tensile test measurement. The factors studied were: the ratio of tannin solutionlignin, pressing time, pressure, pressing temperature.

- To evaluate the effect of tannin-lignin ratio, four different adhesive formulations were tested using commercial mimosa tannin solution and glyoxalated ammonium lignosulfonates: 0-100\%, 75-25\%, 50-50\% and $100-0 \%$. The pressure used to prepare plywood panels was 12 bar at $130^{\circ} \mathrm{C}$ during 4 min.

- Three pressing time were tested using the third adhesive formulation with $75 \%$ of mimosa tannin solution and $25 \%$ of glyoxalated ammonium lignosulfonates: $4 \mathrm{~min}, 7 \mathrm{~min}$ and $10 \mathrm{~min}$. The pressure used was $12 \mathrm{bar}$ at $130{ }^{\circ} \mathrm{C}$.

- To evaluate the pressure effect on the bonding quality of plywood panels, six pressures were tested $(6,8$, $10,12,16$ and 18 bar) using the adhesive with $75 \%$ of mimosa tannin solution and $25 \%$ of glyoxalated ammonium lignosulfonates. The pressing duration was $4 \mathrm{~min}$ under a temperature of $130^{\circ} \mathrm{C}$.

- Four pressing temperature were tested using the adhesive with $75 \%$ of mimosa tannin solution and $25 \%$ of glyoxalated ammonium lignosulfonates: $110{ }^{\circ} \mathrm{C}$, $130{ }^{\circ} \mathrm{C}, 150{ }^{\circ} \mathrm{C}$ and $170{ }^{\circ} \mathrm{C}$. The pressure used was 12 bar during 4 min.

\subsection{Plywood panels preparation and Bonding properties tests}

Plywood panel preparation was carried out according to the requirements of the British standard NBS 1204 [18]. Five panels were tested and the solid contents of adhesives were determined according to EN 827 [19]. The tensile and shear tests were carried out using Universal machine. The adhesives bonding properties were evaluated according to requirement of European Standard EN 314-1 [20] and EN 314-2 [21]. The shear and the tensile tests were carried out without water preconditioning.

\subsection{Formaldehyde test emission}

The formaldehyde emission test was carried out according to the EN 712-2 [22], gas analysis method. The tests were 
N. Rhazi et al.: Physico-mechanical properties of plywood bonded with ecological adhesives

Table 1. Result of screening factors to improve bonding quality of plywood.

\begin{tabular}{|c|c|c|c|}
\hline Factor studied & Identification test & $\begin{array}{c}\text { Tensile test : maximum } \\
\text { rupture }(\mathrm{N})\end{array}$ & Solid content (\%) \\
\hline \multirow{4}{*}{$\begin{array}{l}\text { Tannin - lignin } \\
\text { ratio }\end{array}$} & $\mathbf{F}_{1}:$ Mimosa-NH${ }_{4}$ LSLG/100:0 & $2173 \pm 233^{\mathrm{a}}$ & $34.3 \pm 0.9^{\mathrm{a}}$ \\
\hline & $\mathbf{F}_{2}:$ Mimosa-NH${ }_{4} L S L G / 75: 25$ & $2637 \pm 468^{\mathrm{a}}$ & $42.5 \pm 1.8^{\mathrm{a}}$ \\
\hline & $\mathbf{F}_{3}:$ Mimosa-NH 4 LSLG/50:50 & $2403 \pm 293^{\mathrm{a}}$ & $34.3 \pm 0.7^{\mathrm{a}}$ \\
\hline & $\mathbf{F}_{4}:$ Mimosa- $\mathrm{NH}_{4} \mathrm{LSLG} / 0: 100$ & $495 \pm 218^{\mathrm{a}}$ & $30.2 \pm 2.1^{\mathrm{a}}$ \\
\hline Pressure time & $\mathbf{T}_{1}: 4 \min$ & $2637 \pm 468^{\mathrm{b}}$ & $30.2 \pm 1.9^{\mathrm{a}}$ \\
\hline Mimosa- $\mathrm{NH}_{4} \mathrm{LSLG}$ & $\mathbf{T}_{2}: 7 \mathrm{~min}$ & $3079 \pm 285^{\mathrm{b}}$ & $30.4 \pm 2.2^{\mathrm{a}}$ \\
\hline$(75: 25)$ & $\mathbf{T}_{3}: 10 \mathrm{~min}$ & $2423 \pm 737^{\mathrm{b}}$ & $30.1 \pm 1.7^{\mathrm{a}}$ \\
\hline Pressure & $\mathbf{P}_{1}: 6$ bar & $1639 \pm 108^{\mathrm{a}}$ & $30.2 \pm 1.9^{\mathrm{a}}$ \\
\hline Mimosa-NH${ }_{4} \mathrm{LSLG}$ & $\mathbf{P}_{2}: 8$ bar & $1752 \pm 145^{\mathrm{a}}$ & $30.2 \pm 1.6^{\mathrm{a}}$ \\
\hline \multirow[t]{4}{*}{$(75: 25)$} & $\mathbf{P}_{3}: 10 \mathrm{bar}$ & $2223 \pm 130^{\mathrm{a}}$ & $30.2 \pm 1.8^{\mathrm{a}}$ \\
\hline & $\mathbf{P}_{4}: 12$ bar & $2777 \pm 468^{\mathrm{a}}$ & $30.2 \pm 1.9^{\mathrm{a}}$ \\
\hline & $\mathbf{P}_{5}: 16 \mathrm{bar}$ & $2571 \pm 240^{\mathrm{a}}$ & $30.2 \pm 1.7^{\mathrm{a}}$ \\
\hline & $\mathbf{P}_{6}: 18 \mathrm{bar}$ & $2464 \pm 254^{\mathrm{a}}$ & $30.2 \pm 1.8^{\mathrm{a}}$ \\
\hline Pressure & $\mathbf{T}^{\circ}{ }_{1}: 110{ }^{\circ} \mathrm{C}$ & $1610 \pm 179^{\mathrm{a}}$ & $41.1 \pm 0.9^{\mathrm{a}}$ \\
\hline temperature & $\mathbf{T}_{2}^{\circ}: 130{ }^{\circ} \mathrm{C}$ & $2637 \pm 268^{\mathrm{a}}$ & $41.1 \pm 0.9^{\mathrm{a}}$ \\
\hline Mimosa-NH ${ }_{4}$ LSLG & $\mathbf{T}^{\circ}{ }_{3}: 150{ }^{\circ} \mathrm{C}$ & $3217 \pm 129^{\mathrm{a}}$ & $41.1 \pm 0.9^{\mathrm{a}}$ \\
\hline$(75: 25)$ & $\mathbf{T}^{\circ}{ }_{4}: 170{ }^{\circ} \mathrm{C}$ & $2332 \pm 202^{\mathrm{a}}$ & $41.1 \pm 0.9^{\mathrm{a}}$ \\
\hline
\end{tabular}

${ }^{*}$ a: High significant variance at the level $95 \%, F_{0.05}(3 ; 16)=5.32$ for tannin - lignin ratio; and pressure temperature; $F_{0.05}(5 ; 24)=2.92$ for pressure test; ANOVA test.

${ }^{*}$ b: No significant variance between various time pressure at the level $95 \%, F_{0.05}(2 ; 12)=3.88$; ANOVA test.

performed after conditioning plywood panels for 7 days in room maintained at a relative humidity of $60 \pm 5 \%$ and temperature of $20 \pm 2{ }^{\circ} \mathrm{C}$. In order to evaluate the conformity of the bonding quality of plywood panels in terms of formaldehyde emission, the standard deviation between two tests for $4 \mathrm{~h}$ must be less than 0.5 and the formaldehyde content must be less than $8 \mathrm{mg} / \mathrm{m}^{2} \mathrm{~h}$, According to the requirements of EN 717-2.

\subsection{Statistical analysis}

Ten trials were carried out for each test to evaluate the quality of results. The data are represented as mean \pm standard deviation values. Analysis of variance (ANOVA) was used to evaluate the effect of resin solid content, mechanical quality and bonding properties for plywood panels (maximal rupture for tensile and shear strength test). All the statistical analyses were carried out at $P<0.05$ significance level.

\section{Results and discussion}

\subsection{Results of screening factors}

The effects of significant factors, which improve the adhesives bonding properties, were evaluated using the solid content of adhesives and tensile test measurement. The factors studied were: the ratio of tannin solutionlignin, pressing time, pressure and pressing temperature. The solid contents and mechanical strength of adhesives formulations elaborated in screening factors are shown in Table 1 . The mean value and the significant difference between plywood panels test are also presented by letter in Table 1.
The result of screening factors shows that the progression time pressing does not affect the bonding quality of plywood panels, ANOVA test, Table 1 . This is the reason to choose $4 \mathrm{~min}$ at time pressing for the following test. Also, the resin solid content does not affect the bonding quality of plywood panels. The second observation raised by this study was that the adhesives formulation with only glyoxalated lignin and hardener does not resist to the tensile test for plywood panels, because their high fluidity (the fourth adhesive formulation, Mimosa$\mathrm{NH}_{4}$ LSLG/0:100). The addition of $25 \%$ of glyoxalated lignin in mimosa tannin solution improve the tensile measurement of plywood panels (2637 N), compared the adhesive formulation using only mimosa tannin solution $(2173 \mathrm{~N})$. Nevertheless, when we add $50 \%$ of glyoxalated lignin in adhesive formulation the rupture of plywood panels decreases to $(2403 \mathrm{~N})$. This study shows that the best ratio of mimosa tannin and glyoxalated lignin was $75-25 \%$. This ratio will be used to evaluate the effect of time pressure, temperature pressure and pressure applied to prepare plywood panels. The progression pressure to 6 bar at 12 bar gives the twice tensile measurement (Fig. 2). The rupture of plywood panels cross from $1639 \mathrm{~N}$ to 2777 N. But, when we exceed this pressure to 18 bar, the tensile measurement of plywood panels decreased to $2464 \mathrm{~N}$. In addition, the progression temperature pressure to $110{ }^{\circ} \mathrm{C}$ at $150{ }^{\circ} \mathrm{C}$ gives the twice tensile measurement of plywood panels. The rupture of plywood panels cross from $1610 \mathrm{~N}$ to $3217 \mathrm{~N}$ respectively for $110^{\circ} \mathrm{C}$ and $150{ }^{\circ} \mathrm{C}$. So, higher temperature means more energy to cross-link molecules of the tannin prepolymer and functional groups with each other, and that is why the physical properties improve with increasing press temperature. This can be explained by the faster reactivity of functional groups of wattle tannins and hardener with increasing 


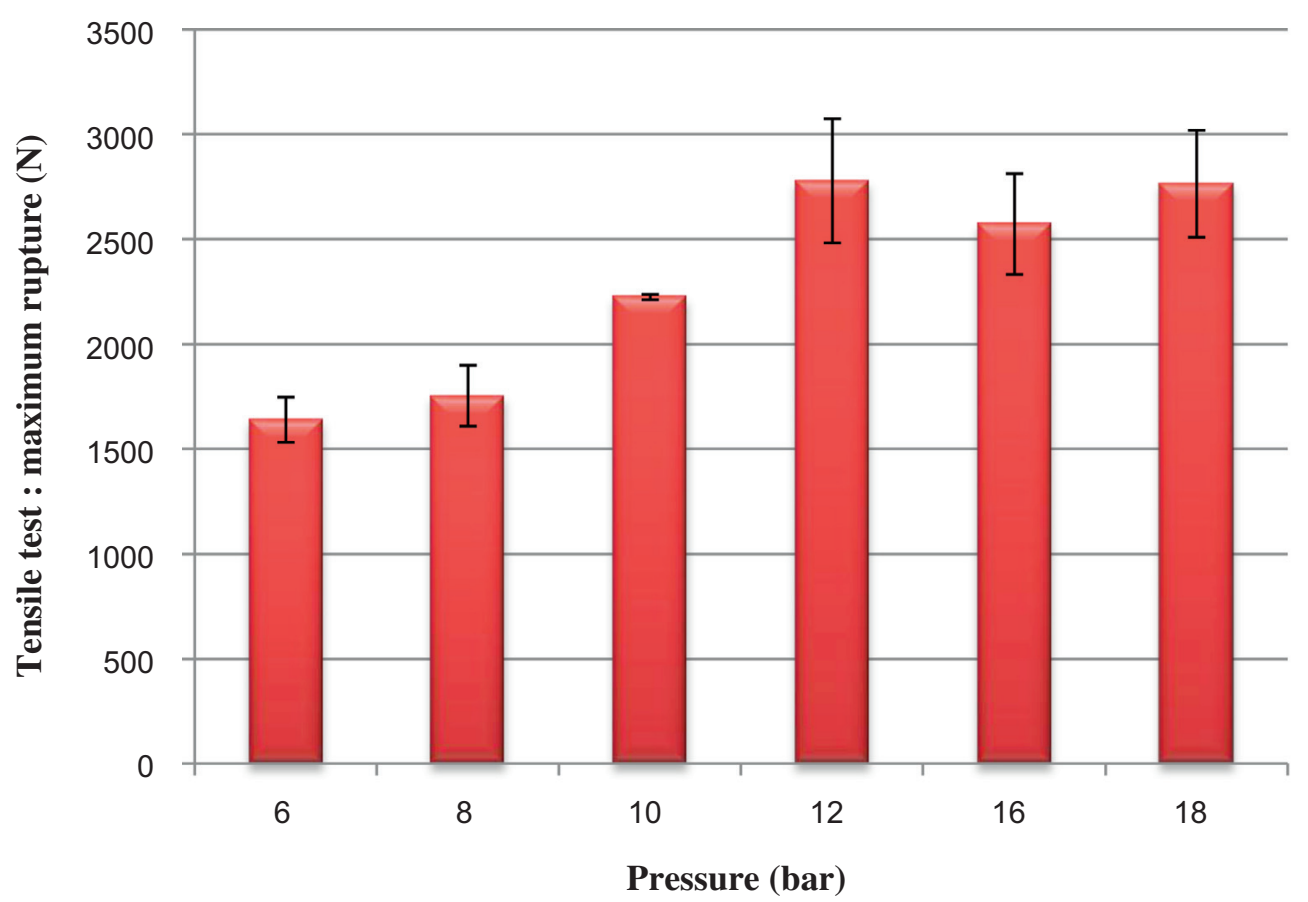

Fig. 2. Effect of pressure on bonding quality of plywood panels.

temperature $[12,23]$. However, when the pressure temperature achieves $170{ }^{\circ} \mathrm{C}$ we remark that the tensile measurement of plywood panels decreases to $2332 \mathrm{~N}$. This result can be explained by the thermal degradation of the surface panels with the increase press temperature to $170{ }^{\circ} \mathrm{C}$, because curing has already taken place. Another study carried out on particleboards panels bonded with wattle tannin-based adhesives, confirms that the physical properties of theses panels decrease with increasing press temperature from $160{ }^{\circ} \mathrm{C}$ to $190{ }^{\circ} \mathrm{C}[12]$.

The mean factor that significantly affected the mechanical properties of plywood panels were tanninlignin ratio, pressure and temperature pressure, ANOVA test, Table 1 . These factors are the best significant factors to improve mechanical properties of plywood panels and to improve bonding quality of plywood panels. The best condition gives the highest mechanical properties of plywood panels and maximal tensile measurement $(2637 \mathrm{~N})$ was the ratio of mimosa tannin solution and glyoxalated lignin $(75-25 \%)$, time pressure, 4 min, temperature pressure, $150{ }^{\circ} \mathrm{C}$ and pressure applied to prepare plywood panels was 12 bar.

\subsection{Comparison bonding commercial adhesives}

The effectiveness of tannins and lignin adhesives was compared to commercial adhesives used for bonding plywood, such as: UF and PF. The formulation with only mimosa tannin was also added, to mark the effect of addition of lignosulfonate to bio-based adhesives. The comparative study is shown in Table 2. The results were further evaluated by ANOVA test indicated high significant on the shear properties, Table 2 and Figure 3.

The comparative study shows that the addition of glyoxalated lignin in tannin solution adhesives improves their mechanical property. The tensile measurement crosses from $2173 \mathrm{~N}$ to $2637 \mathrm{~N}$, respectively for mimosa tannin adhesives and mimosa tannin-glyoxalated lignin (75-25\%). In addition, the tensile measurement of this adhesive formulation is very closes than the measure using commercial adhesives widely used to bonding plywood, (Fig. 3). The mechanical property of this formulation $(2637 \mathrm{~N})$ was higher than commercial urea formaldehyde $(2528 \mathrm{~N})$ and slightly lower than phenol formaldehyde $(2882 \mathrm{~N})$ for maximal rupture of plywood panels. The use of condensed tannins obtained from various extraction methods, shows a few difference in tensile tests. However, in the other hand, all formulations with extracted Acacia mollissima tannins presented higher resistance shear forces that exceed $1 \mathrm{~N} / \mathrm{mm}^{2}$ (Fig. 4). So, according to the requirements of EN 314-1:2004, all these formulations presented good bonding quality of plywood panels and higher mechanical properties. These results show the good mechanical performances of the adhesives prepared laboratory scale using glyoxalated lignins and natural tannin extracted from Moroccan bark of Acacia mollissima.

\subsection{Results of formaldehyde emission}

The formaldehyde emission results for plywood panels glued with the different adhesives prepared are presented in Table 3 . 
N. Rhazi et al.: Physico-mechanical properties of plywood bonded with ecological adhesives

Table 2. Comparison of bonding commercial adhesives.

\begin{tabular}{lcccc}
\hline Adhesives formulation & $\begin{array}{c}\text { Tensile test: } \\
\text { maximum rupture }(\mathrm{N})\end{array}$ & $\begin{array}{c}\text { Shear resistance } \\
\text { force }\left(\mathrm{N} / \mathrm{mm}^{2}\right)\end{array}$ & $\begin{array}{c}\text { Solid content } \\
(\%)\end{array}$ & $\begin{array}{c}\text { Viscosity } \\
(\mathrm{cp})\end{array}$ \\
\hline $\begin{array}{l}\text { Commercial mimosa tannin } \\
\text { solution }\end{array}$ & $2173 \pm 233^{\mathrm{a}}$ & $3.48 \pm 0.20^{\mathrm{a}}$ & $38.3 \pm 0.3^{\mathrm{a}}$ & $447.7 \pm 7.2^{\mathrm{a}}$ \\
$\begin{array}{l}\text { Commercial mimosa tannin }- \\
\text { glyoxalated lignin (70-25\%) }\end{array}$ & $2637 \pm 268^{\mathrm{a}}$ & $4.22 \pm 0.42^{\mathrm{a}}$ & $30.2 \pm 0.2^{\mathrm{a}}$ & $410.2 \pm 2.4^{\mathrm{a}}$ \\
$\begin{array}{l}\text { Maceration Mimosa tannin }- \\
\text { glyoxalated lignin (70-25\%) }\end{array}$ & $1364 \pm 85.4^{\mathrm{a}}$ & $2.18 \pm 0.14^{\mathrm{a}}$ & $43.1 \pm 1.3^{\mathrm{a}}$ & $428.9 \pm 2.0^{\mathrm{a}}$ \\
$\begin{array}{l}\text { Infusion Mimosa tannin - } \\
\text { glyoxalated lignin (70-25\%) }\end{array}$ & $1270 \pm 42.4^{\mathrm{a}}$ & $2.03 \pm 0.07^{\mathrm{a}}$ & $38.1 \pm 4.7^{\mathrm{a}}$ & $389.7 \pm 5.7^{\mathrm{a}}$ \\
$\begin{array}{l}\text { Microwave Mimosa tannin - } \\
\text { glyoxalated lignin (70-25\%) }\end{array}$ & $989 \pm 67.3^{\mathrm{a}}$ & $1.58 \pm 0.11^{\mathrm{a}}$ & $37.3 \pm 5.1^{\mathrm{a}}$ & $392.4 \pm 6.6^{\mathrm{a}}$ \\
$\begin{array}{l}\text { Urea formaldehyde (UF) } \\
\text { Phenol formaldehyde (PF) }\end{array}$ & $2528 \pm 239^{\mathrm{a}}$ & $4.04 \pm 0.38^{\mathrm{a}}$ & $57.2 \pm 0.3^{\mathrm{a}}$ & - \\
\hline
\end{tabular}

${ }^{*}$ a: High significant variance at the level $95 \%, F_{0.05}(5 ; 24)=3.90$; ANOVA test.

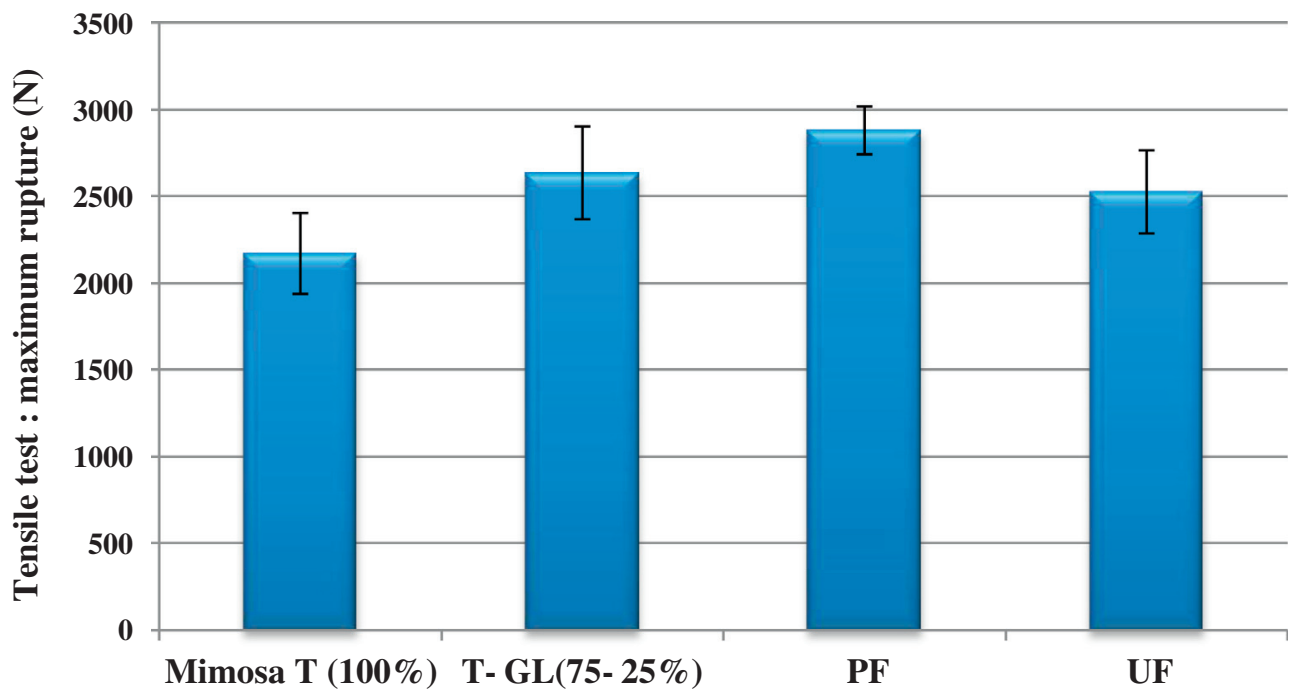

Fig. 3. Comparison of maximum rupture of commercial and bio-adhesives using for bonding plywood panels.

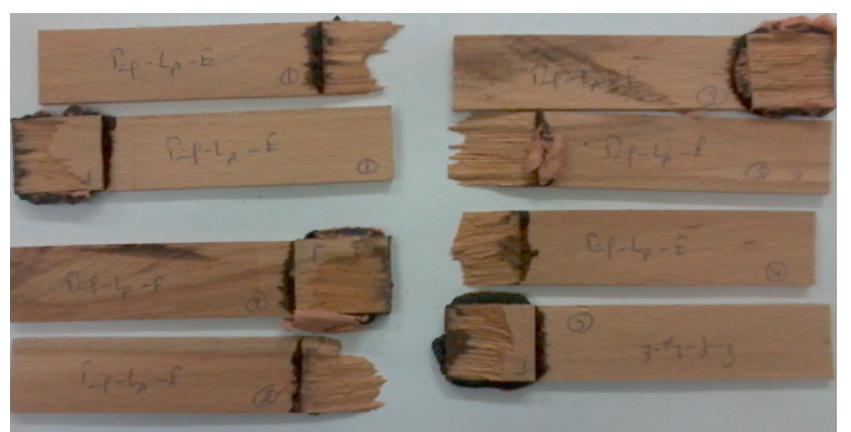

Fig. 4. Mechanical propriety of adhesives with Mimosa tanninglyoxalated lignin.

Table 3 shows that the formaldehyde contents of bio-based adhesives made using glyoxalated lignin and mimosa tannin, are however, considerably lower than the formulation made with only mimosa tannin. No significant differences were noticeable between the formaldehyde emission obtained for the plywood panels prepared with the three bio-based adhesives made with condensed tannins extracted from Moroccan bark of Acacia mollissima and the only wood panels heated at $150{ }^{\circ} \mathrm{C}$. Thus according to the requirements of European Standard, all formulations elaborated in laboratory scale were considerate environmental friendly adhesives, and they have $\mathrm{E}_{1}$ grade level (the standard deviation between two tests for $4 \mathrm{~h}$ was less than 0.5 and the Formaldehyde content were less than $3.5 \mathrm{mg} / \mathrm{m}^{2} \mathrm{~h}$; Tab. 3). Also, the plywood panels bonded with glyoxalated lignin and mimosa tannin showed $24-67 \%$ reductions in formaldehyde emission compared to plywood prepared with commercial PF resins (respectively for the mimosa tannin (100\%)) and the maceration mimosa tannin- glyoxalated lignin. Therefore, it can be concluded that resins based on renewable resources such as glyoxalated lignosulfonates and Acacia mollissima tannins have potential as a substitute synthetic adhesives based on phenol-formaldehyde. 
Table 3. Formaldehyde emission results for plywood panels prepared with the experimental adhesives.

\begin{tabular}{lccc}
\hline Adhesives formulation & $\begin{array}{c}\text { Formaldehyde content }\left(\mathrm{mg} / \mathrm{m}^{2} \mathrm{~h}\right) \\
\text { Mean } \pm S D\end{array}$ & $\begin{array}{c}\text { Conclusion test } \\
(\text { EN 717-2) }\end{array}$ & $\begin{array}{c}\text { Class of } \\
\text { emission }\end{array}$ \\
\hline PF & $2.78 \pm 0.45$ & Conform & $\mathrm{E}_{1}$ \\
Mimosa T (100\%) & $2.11 \pm 0.25$ & Conform & $\mathrm{E}_{1}$ \\
T- GL (75-25\%) & $1.27 \pm 0.08$ & Conform & $\mathrm{E}_{1}$ \\
Mac T-GL (75-25\%) & $0.91 \pm 0.03$ & Conform & $\mathrm{E}_{1}$ \\
Inf T-GL (75-25\%) & $0.94 \pm 0.18$ & Conform & $\mathrm{E}_{1}$ \\
MW T-GL (75-25\%) & $1.07 \pm 0.03$ & Conform & $\mathrm{E}_{1}$ \\
Wood only control & $0.62 \pm 0.08$ & Conform & $\mathrm{E}_{1}$ \\
\hline
\end{tabular}

$S D$ : Standard deviation. Mac T-GL: Maceration mimosa tannin-glyoxalated lignin. Inf T-GL: Infusion mimosa tannin- glyoxalated lignin. MW T-GL: Microwave mimosa tannin- glyoxalated lignin.

\section{Conclusion}

The present investigation, on the use of glyoxalated lignin and tannin to prepare a natural wood adhesive, shows that plywood panels bonded with mimosa tannin and glyoxalated lignin adhesive showed comparable mechanical properties to the panels made with the commercial UF and PF resins. The obtained performances satisfied the exigencies of plywood panels for interior fittings used in dry medium $\left(\mathrm{P}_{2}\right)$ according to European norms EN 314-1 (2004) [20]. Moreover, the formaldehyde emission levels obtained from boards bonded with glyoxalated lignin and mimosa tannin adhesive were considerably lower to these obtained from boards made with commercial PF. Physicomechanical studies have shown that tannin- lignin ratio, pressure and temperature pressure exhibit an excellent mechanical properties for plywood panels. The best performance was obtained using $75 \%$ of mimosa tannin and $25 \%$ of glyoxalated lignin made during $4 \mathrm{~min}$ at $150{ }^{\circ} \mathrm{C}$ and 12 bar.

We gratefully acknowledge the financial support of "Partenariat Hubert Curien, PHC Volubilis, (EGIDE)", "Centre National de Recherche Scientifique et Technique (CNRST) from MOROCCO and "Agence Nationale de la recherche (ANR-10-EQPX-16 Xyloforest)". We also gratefully acknowledge the generosity of Silvachimica and Tembec for providing us raw materials.

\section{References}

1. T. Sellers, Forest. Prod. J. 51, 12 (2001)

2. J. Gomez-Bueso, R. Haupt, Wood Composite Adhesives, (Springer, Berlin Heidelberg, 2010), Chap. 8

3. I.H. Keith, W.I. Telliard, Environ. Sci. Technol. 13, 416 (1979)

4. G.E. Myers, Forest. Prod. 77, 80 (1986)

5. A. Pizzi, J. Adhesion Sci. Technol. 20, 829 (2006)

6. A. Pizzi, P. Tekely, J. Appl. Polym. Sci. 56, 1645 (1995)
7. F. Pichelin, M. Nakatani, A. Pizzi, S. Wieland, A. Despres, S. Rigolet, Forest Prod. J. 56, 31 (2006)

8. L. Yuan, L. Kaichang, Int. J. Adhes. Adhes. 27, 59 (2007)

9. A. Moubarik, A. Allal, A. Pizzi, F. Charrier, B. Charrier, Maderas Cienc. Tecnol. 12, 189 (2010)

10. L. Chupin, B. Charrier, A. Pizzi, A. Perdomo, F. Charrier-El Bouhtoury, J. Therm. Anal. Calorim. 119, 1577 (2015)

11. P.M. Stefani, C. Peña, R.A. Ruseckaite, J.C. Piter, I. Mondragon, Bioresour. Technol. 99, 5977 (2008)

12. S. Kim, Y.K. Lee, H.-J. Kim, H.H. Lee, J. Adhes. Sci. Technol. 17, 1863 (2003)

13. Z. Kebbi, F. Michenot, Quality Indoor Air in the Presence of Eco Particleboards Panels (Nancy University, 2011), p. 1

14. P. Navarrete, H.R. Mansouri, A. Pizzi, S. Tapin-Lingua, M.B. Benjelloun, H. Pasch, J. Adhes. Sci. Technol. 24, $1597(2010)$

15. R. El Hage, N. Brosse, P. Navarrete, A. Pizzi, J. Adhes. Sci. Technol. 25, 1549 (2011)

16. M.N. Belgacem, A. Gandini, Monomers, Polymers and Composites from Renewable Resources (Elsevier, 2008), Chap. 9

17. N. Rhazi, M. Oumam, H. Hannache, A. Sesbou, B. Charrier, A. Pizzi, F. Charrier-El Bouhtoury, Ind. Crops Products 70, 245 (2015)

18. British standard NBS 1204. Specification for MR phenolic and aminoplastic synthetic resin adhesives for wood (1993)

19. British standard EN 827. Adhesives: Determination of Conventional Solids and Constant Mass Solids (2006)

20. French standard EN 314-1. Plywood: Bond Quality. Part 1: Test Methods (2004)

21. French standard EN 314-2. Plywood: Bond Quality. Part 2: Requirements (1993)

22. French standard EN 717-2. Wood-Based panels: Determination of Formaldehyde Release. Part 1: Formaldehyde Emission by the gas analysis method (2011)

23. J. Gao, Y. Liu, L. Yang, Polym. Degrad. Stab. 63, 19 (1999) 